\title{
KEPERCAYAAN MASYARAKAT BUGIS PRA ISLAM
}

\author{
Ridhwan \\ Institut Agama Islam Negeri Bone, Indonesia \\ e-mail: ridhwandr@gmail.com
}

\begin{abstract}
This article discusses pre-Islamic Bugis community beliefs. There are issues discussed, namely the origins of Bugis society and pre-Islamic Bugis community beliefs. The results of the discussion show that the Bugis people who inhabited more than half of South Sulawesi's territory could be traced to tens of thousands of years before Christ. They are known as a combination of Austro Melanesoid races, Abris Sous Roche, and Paleo Mongoloid that inhabited this island around 40,000 to 30,000 years ago. Then followed by the Austronesians who came around 3000 years BC. come in waves. Their beliefs experience dynamics. At first they may believe that all objects in this nature have magical powers in the form of spirits, so that they can be called adherents of animism and dynamism. However, in subsequent developments there were strong indications that Bugis community trust had influence from Hinduism and Buddhism. This is indicated by the many instillations of the two religious traditions used by the pre-Islamic Bugui community, for example Dewata, Bathara, Sri Sangyang, Bissu, and others. Therefore, some experts say that their beliefs can be referred to as monolatry, or Uhr-Monotheism (ancient monotheism).
\end{abstract}

\section{Kata Kunci: Bugis, Kepercayaan, Pra Islam}

\section{PENDAHULUAN}

Keanekaragaman adalah kunci terpenting dari sistem kepercayaan dan upacara bagi masyarakat yang tidak memiliki tradisi tertulis. Ini bukan hanya karena setiap wilayah, komunitas, atau desa memiliki petugas agama dan nilai-nilainya sendiri, tetapi masing-masing orang bersikap pragmatis dan eksperimental dalam menjelaskan dan menghadapi kekuatan-kekuatan spiritual. Secara umum para etnograf menghadapi kesulitan yang tidak sedikit ketika mencoba meneliti bentuk-bentuk kepercayaan masyarakat Asia Tenggara, karena begitu banyak ragam dan coraknya. Antara satu 
daerah dengan daerah lainnya memiliki cara dan bentuk kepercayaan sendiri-sendiri. Walaupun demikian, tidaklah berarti bahwa mereka tidak menemukan prinsip-prinsip yang dapat dijadikan ciri umum kepercayaan masyarakat di wilayah ini. ${ }^{1}$

Anthony Reid mengungkapkan bahwa seperti halnya masa pramodern di wilayah-wilayah lainnya, di Asia Tenggara tidak ada perbedaan antara dimensi agama dan sekuler. Dunia materi dipenuhi oleh kekuatankekuatan spiritual (roh-roh), dan agar bisa hidup dan bertahan di dalamnya, setiap orang harus bisa memanipulasinya. Dalam konteks ini, secara umum agama Asia Tenggara hanya bisa dipahami sebagai bagian dari setiap kejadian yang penting dalam kehidupan sehari-hari. Meskipun begitu, terdapat ciri umum kepercayaan masyarakat Asia Tenggara pra Islam, yakni adanya pemujaan terhadap roh-roh, melalui berbagai bentuk pesta dan pengorbanan. Berbagai bentuk pesta dan pengorbanan tersebut diyakini mampu menjamin agar roh-roh tersebut bersimpatik terhadap masalah pribadi apapun, seperti penyembuhan orang sakit, pelayaran yang menguntungkan bagi mereka yang mengarungi lautan, panen yang baik, dan kehidupan suami istri yang bahagia. ${ }^{2}$

Secara umum kepercayaan masyarakat Asia Tenggara bertumpu pada paham tentang adanya roh-roh. Roh-roh tersebut pada dasarnya bersifat abstrak, namun diyakini bersemayam dalam benda-benda kongkret, baik benda mati maupun benda hidup. Demikian juga roh-roh tersebut diyakini berpengaruh kuat kepada segala bentuk kegiatan manusia, baik pada saat mereka hidup maupun setelah mereka meninggal. Konsep kepercayaan inilah yang digambarkan oleh Anthony Reid ketika menjelaskan kepercayaan masyarakat Asia Tenggara, yakni seluruh dunia materi digerakkan oleh rohroh yang harus dipelihara dan dibujuk. Keberadaan roh-roh tersebut sebagai bagian dari kesatuan kosmos, roh penggerak tunggal. Konsep inilah yang oleh

${ }^{1}$ Lihat Anthony Reid, Southeast Asia in the Age of Commerce 1450-1680 (Asia Tenggara dalam Kurun Niaga 1440-1680), trj., R. Z. Leirissa dan P. Soemitro, Jilid 2 (Cet. II; Jakarta: Yayasan Obor Indonesia, 2011), h. 161.

${ }^{2}$ Lihat Anthony Reid, Southeast Asia in the Age of Commerce 1450-1680 (Asia Tenggara dalam Kurun Niaga 1440-1680), h. 162. 
para ahli modern disebut sebagai anima atau animisme. Kemudian ada juga yang mengatakan "aliran hidup", "aliran jiwa", "kekuatan magis", dan akhirnya "dinamisme". ${ }^{3}$

Pada pembahasan selanjutnya, akan dikemukakan dua pokok bahasan, yakni (1) asal usul masyarakat Bugis dan (2) kepercayaan masyarakat Bugis pra Islam:

\section{Asal Usul Manusia Bugis}

Dewasa ini, orang Bugis umumnya selalu mengidentifikasikan diri mereka berdasarkan kerajaan-kerajaan Bugis besar yang pernah ada, yakni Bone, Wajo, Soppeng dan Sidenreng, serta beberapa persekutuan kerajaan kecil, seperti yang terdapat di sekitar Pare-Pare dan Suppa (Pinrang) serta di pantai barat sampai Barru dan wilayah Sinjai serta Bulukumba di sebelah selatan. Pengelompokan ini dimaksudkan untuk membedakannya dengan etnis Sulawesi Selatan lainnya, misalnya Makassar, Mandar, dan Toraja. ${ }^{4}$ Meskipun demikian, dalam ungkapan sehari-hari, istilah Bugis sering digandengkan dengan etnis Makassar, sehingga menjadi Bugis-Makassar. Menurut Andi Rasdiyanah, pengungkapan seperti itu disebabkan karena kedua suku tersebut merupakan satu kesatuan etnik kebudayaan yang dikenal dengan nama Bugis-Makassar. ${ }^{5}$

Penggunaan istilah "orang Bugis" atau "Bugis" sendiri tidak ditemukan keterangan yang memadai, sebab hingga dewasa ini bagi orang yang disebut "orang Bugis" sendiri jika mereka menyebut dirinya tidak menyebut dengan istilah "Bugis" atau "orang Bugis", tetapi menggunakan istilah "Ugi" atau To Ugi". Demikian juga karya-karya orang Bugis masa lalu, seperti dalam lontara. Namun demikian, ada kemungkinan bahwa istilah Bugis adalah evolusi dari istilah $U g i$ '. Istilah $U g i$ ' berasal dari akhir kata nama seorang pemimpin wilayah

\footnotetext{
${ }^{3}$ Lihat Anthony Reid, Southeast Asia in the Age of Commerce 1450-1680 (Asia Tenggara dalam Kurun Niaga 1440-1680), h. 163.

${ }^{4}$ Lihat Christian Perlas "The Bugis", trj. Abdul Rahman Abu dkk, Manusia Bugis (Cet. II; Jakarta: Nalar bekerja sama dengan Forum Jakarta-Faris, EFEO, 2005), h. 14-15.

${ }^{5}$ Andi Rasdiyanah, "Integrasi Sistem Pangngaderreng (Adat) dengan Sistem Syari'at sebagai Pandangan Hidup Orang Bugis dalam Lontaraq Latoa" (Disertasi Doktor, Program Pascasarjana Institut Agama Islam Negeri Sunan Kalijaga, Yogyakarta, 1995), h. 2.
} 
Cina yang disebutkan dalam I La Galigo, ${ }^{6}$ yakni La Sattumpugi'. Menurut Lontarak Attoriolongennge Pammana disebutkan bahwa pada awalnya suku yang kemudian disebut Bugis atau To Ugi masih merupakan bagian dari suku To Luwu'. Di bawah pimpinan La Sattumpugi', kelompok suku ini pindah ke daerah Cenrana (salah satu Kecamatan di Kabupaten Bone Sekarang), lalu sebagian pindah ke daerah Pammana (salah satu Kecamatan di Kabupaten Wajo sekarang). Wilayah kekuasaan La Sattumpugi' yang masuk daerah Bone (Cenrana) kemudian dinamakan Cina ri Lau dan daerah yang masuk dalam wilayah Wajo (Pammana) kemudian dinamakan Cina ri Aja. La Sattumpugi' sendiri adalah pemimpin pertama dari wilayah yang dikenal dalam I La Galigo sebagai daerah Cina, sehingga ia digelar sebagai Datunna atau Opunna Cina. ${ }^{7}$

Pada masa I La Galigo orang Bugis disebut dengan To Cina atau orang yang mendiami wilayah Cina, baik Cina ri Aja maupun Cina ri Lau', yang pemimpin pertamanya adalah La Sattumpugi'. Sebutan ini dimaksudkan untuk membedakan mereka dengan beberapa kelompok manusia yang mendiami wilayah-wilayah lainnya, yakni wilayah Luwu disebut To Luwu, wilayah Mandar disebut To Manre, dan seterusnya. Walaupun secara umum terdapat kesamaan budaya dan tradisi di antara orang-orang yang mendiami wilayah Sulawesi Selatan, namun berdasarkan fakta-fakta yang hingga saat ini dapat disaksikan bahwa pada masa-masa awal tersebut lambat laun telah membentuk budaya dan tradisi tersendiri. Akhirnya, terbentuklah entitas-entitas etnis Sulawesi Selatan sebagaimana yang ada hingga dewasa ini.

Dengan demikian, istilah Bugis yang menunjuk kepada To Ugi atau To Cina pada masa I La Galigo tersebut adalah sebuah istilah yang dapat diduga kuat muncul belakangan, yakni ketika mereka berinteraksi dengan orang-orang di luar komunitasnya. Hal ini dapat diamati dari istilah yang digunakan oleh orang Mandar ketika menyebut orang Bugis hingga dewasa ini, yakni istilah To Bugis, bukan To Ugi'. Hal lain yang dapat dijadikan alasan untuk memperkuat

${ }^{6}$ Dalam I La Galigo diceritakan bahwa We'Cudai, salah seorang istri dari Sawerigading, berasal dari kerajaan Cina. Lihat R.A. Kern, I La Galigo (Cet. II; Yogyakarta: Gadjah Mada University Press, 1993), h. 244.

${ }^{7}$ Andi Rasdiyanah, "Integrasi Sistem Pangngaderreng (Adat) dengan Sistem Syari'at sebagai Pandangan Hidup Orang Bugis dalam Lontaraq Latoa", h. 40. 
kesimpulan ini adalah bahwa istilah yang digunakan oleh Portugis ketika pertama kali mengunjungi daerah Sulawesi Selatan pada abad ke-16 adalah istilah Bougius. $^{8}$ Istilah ini, dapat dipastikan merujuk pada kata Bugis, bukan Ugi'.

Asal-usul manusia Bugis atau To-Ugi hingga kini masih tidak jelas dan tidak pasti. Berbeda dengan manusia di wilayah Indonesia bagian barat, Sulawesi Selatan sama sekali tidak memiliki monumen Hindu dan Budha atau prasasti, baik dari batu maupun logam, yang memungkinkan dibuatnya satu kerangka acuan yang cukup memadai untuk menelusuri sejarah orang Bugis sejak abad pertama Masehi hingga masa ketika sumber-sumber tertulis Barat cukup banyak tersedia. Sumber tertulis lokal yang dapat diandalkan hanya berisi informasi abad ke-15 dan sesudahnya. Oleh karena itu, umumnya para ahli menyebutkan bahwa masa antara abad ke-1 sampai abad ke-10 M adalah masa-masa gelap sejarah Sulawesi Selatan. ${ }^{9}$

Pernyataan di atas mungkin benar jika dimaksudkan (1) bahwa di wilayah Sulawesi Selatan belum ditemukan cukup bukti adanya sebuah komunitas masyarakat yang terhimpun dalam satu kerajaan, lengkap dengan semua institusinya, seperti halnya di wilayah-wilayah lainnya, seperti Jawa, Sumatera, dan Kalimantan, dan (2) tidak ada bukti-bukti tertulis yang dapat diandalkan untuk menggambarkan masyarakat Sulawesi Selatan sebelum abad ke $10 \mathrm{M}$. Namun demikian, hal tersebut tidaklah berarti sama sekali tidak ada yang dapat dilakukan untuk mengungkap kehidupan masyarakat Sulawesi Selatan dalam masa milenium pertama, bahkan beberapa milenium sebelum tahun Masehi. Dalam hal ini, bukti-bukti arkeologi yang telah ditemukan oleh beberapa peneliti menjadi satu-satunya dasar pijakan.

Para ahli menyebutkan, terdapat bukti-bukti kuat bahwa pulau Sulawesi, khususnya Sulawesi bagian selatan, adalah termasuk daerah penyebaran manusia prasejarah. Para ahli purbakala menduga pulau Sulawesi telah dihuni manusia

${ }^{8}$ Istilah Bougius jelas tertulis dalam peta yang dilukis oleh orang Portugis, Antonio de Paiva tahun 1544 ketika mengunjungi Sulawesi Selatan. Peta tersebut dimuat Christian Perlas, "The Bugis", trj. Abdul Rahman Abu dkk, Manusia Bugis , h. 138.

${ }^{9}$ Lihat M. Farid W. Makkulau, Manusia Bissu (Cet. II; Makassar: Refleksi, 2008), h. 2. 
yang diperkirakan terjadi sejak 10.000 sampai 2000 tahun sebelum Masehi. ${ }^{10}$ Bahkan menurut Van Heekeren bahwa kemungkinan besar wilayah Sulawesi Selatan telah dihuni manusia sejak pertengahan atau penghujung periode Pleistosen akhir, yakni sekitar 50.000 hingga 30.000 tahun sebelum Masehi. Hal tersebut didasarkan pada hasil penelitiannya pada tahun 70-an yang dilakukan pada situs permukaan lembah Sungai Walanae di Cabenge (Soppeng). Di sana, ditemukan berbagai bukti industri alat serpih bersama fosil hewan yang sudah lama punah, seperti stegodon (sejenis gajah kecil). Meskipun Van Heekeren kemudian beranggapan bahwa fosil tersebut tidak berhubungan dengan artefak baru yang ditemukan, dan bahwa artefak itu berasal dari zaman yang jauh lebih belakangan. Akan tetapi ilmuan lain lebih cenderung berpendapat bahwa aktivitas manusia mungkin telah ada di Sulawesi Selatan sejak kira-kira 40.000 tahun lalu. Dengan kata lain, penghuni awal Sulawesi Selatan dianggap sezaman dengan manusia Wajak di Jawa Timur, Manusia Gua Niah di Serawak (Kalimantan) dan temuan-temuan Gua Tabon di Palawan, Filipina Selatan. ${ }^{11}$ Selanjutnya, dalam berbagai penemuan, terutama yang diperoleh dari penggalian gua-gua (cerukceruk peneduh) di sekitar Maros, diketahui bahwa industri serpih awal (Cabenge) ternyata berlanjut di Leang Burung. Di lokasi tersebut ditemukan berbagai jenis lancipan Levallois yang melalui uji karbon pada kulit kerang yang berasosiasi dengan temuan tersebut diperkirakan berasal dari periode antara 30.000 dan 19.000 tahun lalu. $^{12}$

Jika pulau Sulawesi bagian selatan telah dihuni manusia sejak 40.000 sampai dengan 30.000 tahun lalu, maka siapakah mereka itu dan dari mana asalusulnya? Para ahli menyebut mereka sebagai campuran berbagai ras yang datang dari berbagai penjuru, yaitu (1) ras Austro Melanesoid yang datang melalui arah selatan, yakni migrasi dari Pulau Jawa dengan ciri khas kapak genggam yang terbuat dari batu berbentuk lonjong dan senang memakan binatang keras, (2) ras yang datang melalui arah Timur (difusi dari Irian Jaya) dengan ciri khas Abris

\footnotetext{
${ }^{10}$ Lihat Mukhlis P. dkk., Sejarah Kebudayaan Sulawesi (Jakarta: Proyek Inventarisasi dan Dokumentasi Sejarah Nasional, 1995), h. 13-14.

${ }^{11}$ Lihat Christian Perlas, "The Bugis", trj. Abdul Rahman Abu dkk, Manusia Bugis, h. 2324.

${ }^{12}$ Lihat Christian Perlas, "The Bugis”, trj. Abdul Rahman Abu dkk, Manusia Bugis, h. 24.
} 
Sous Roche yang senang melukis di dinding gua dengan warna merah, dan (3) ras Paleo Mongoloid yang datang melalui arah utara (migrasi dari kepulauan Sangir) dengan ciri khas alas-alas plaket dan ujung panah yang sisinya bergerigi. Mereka ini termasuk dalam gelombang penyebaran penduduk Indonesia yang pertama kali dan merupakan pendukung dari kebudayaan mesolitikum. Hubungan antara orang Austro-Melanesoid dengan orang Paleo Mongoloid pada mulanya adalah hubungan antara mereka yang melakukan penaklukan dengan mereka yang ditaklukkan, tetapi lama kelamaan mereka saling berasimilasi untuk kemudian membentuk suatu masyarakat baru. Beberapa ahli menyebut mereka sebagai orang To Ala (To Ale'=Bugis, orang yang ada di hutan?). ${ }^{13}$

Di pulau Sulawesi manusia To Ala (To Ale') melampaui tingkat peradaban zaman batu dengan mata pencaharian berburu binatang di hutan, meramu tumbuhtumbuhan dan akar-akaran, dan menangkap ikan dan kerang di laut. Mereka hidup dalam kelompok-kelompok kecil di muara-muara sungai dekat pantai. Sedangkan tempat tinggal mereka semacam perkampungan yang terdiri dari ceruk atau gua yang menempel pada dinding karang besar. Salah satu kegemaran mereka yang paling umum adalah menghiasi dinding gua dan karang dengan gambar-gambar tangan dan binatang. Pada masa sekarang, bekas perkampungan dan lukisanlukisan mereka masih dapat disaksikan di gua Leang-Leang Kabupaten Maros. ${ }^{14}$

Christian Perlas mengemukakan bahwa peninggalan budaya To Ale’ yang disebut "budaya To Alean" adalah sisa-sisa industri seperti pisau, alat serpih, dan mikrolet. Peninggalan mereka ditemukan pada berbagai gua atau ceruk yang biasanya dihiasi gambar telapak tangan dan binatang (babi). Di dalam gua yang kemungkinan besar hanya mereka gunakan sebagai tempat berteduh sementara saat berburu dan mengumpulkan makanan. Di lokasi sekitarnya banyak ditemukan mata panah, mikrolit geometric, dan lancipan bergagang cekung yang disebut lancipan Maros (Maros point). Alat-alat tersebut dianggap produk industri alat serpih paling halus yang sejauh ini ditemukan di Indonesia. ${ }^{15}$

\footnotetext{
${ }^{13}$ Lihat Christian Perlas, "The Bugis", trj. Abdul Rahman Abu dkk, Manusia Bugis, h. 24.

${ }^{14}$ Lihat Mukhlis P. dkk., Sejarah Kebudayaan Sulawesi, h. 14.

${ }^{15}$ Lihat Mukhlis P. dkk., Sejarah Kebudayaan Sulawesi, h. 14.
} 
Gambaran secara fisik tentang manusia To Ale' dapat diketahui dari penjelasan Christian Perlas bahwa mereka mungkin tidak terlalu berbeda dengan penduduk asli Australia pada masa itu, yakni suku Aborijin. Di Asia Tenggara mereka mengalami penghalusan kepala dan tengkorak kepala, meski tetap memiliki fenotipe Austroloid. Beberapa keturunan dari populasi tersebut tetap bertahan hidup sampai sekarang, misalnya kelompok-kelompok terasing di Malaysia (antara lain orang Sakai), dan di Filipina (seperti orang Aeta), atau sedikit banyak telah berbaur dengan populasi yang datang kemudian. ${ }^{16}$

Gambaran manusia To Ala' juga dapat diketahui dari penjelasan J. Siboro ketika menulis tentang sejarah Australia. J. Siboro menjelaskan bahwa penduduk Australia (suku Aborijin) diperkirakan sebangsa dengan To Ala' di Sulawesi. Penduduk asli Australia dapat dikenali dari ciri-cirinya: kulit berwarna coklat (hitam kalau terbakar mata hari), rambut ikal bergelombang, muka dan tubuh ditumbuhi oleh bulu-bulu yang lebat, dahi sempit dan mundur, rongga mata dalam, alis mata menonjol, rahan menonjol, mulut lebar, tulang tengkorak tebal, tinggi badan rata-rata 5 kaki dan $5 / 6$ inci. Berdasarkan ciri-ciri fisik itu dapat disimpulkan bahwa penduduk asli Australia sebangsa dengan suku To Ala' di Sulawesi, penduduk asli Sumatera, sebagian penduduk Irian, orang Sakai di Malaysia, orang Veddas di Srilangka, dan suku pegunungan asli India Selatan. Mereka diperkirakan berimigrasi dari India dan semenanjung Malaysia, lalu bergerak ke arah selatan melalui Indonesia, dan masuk ke Australia lewat Timor, Laut Ara Pura, kemudian menyeberang ke Selat Torres. ${ }^{17}$

\section{Kepercayaan Masyarakat Bugis Pra Islam}

Anthony Reid ${ }^{18}$ dan Mukhlis dkk. menyebutkan bahwa sebelum datangnya agama Kristen dan Islam masyarakat di wilayah ini telah

\footnotetext{
${ }^{16}$ Lihat Mukhlis P. dkk., Sejarah Kebudayaan Sulawesi, h. 14.

${ }^{17}$ Lihat J. Siboro, Sejarah Australia (Bandung: Tarsito, 1989), h. 6.

${ }^{18}$ Lihat Anthony Reid,
} 
mengenal dan menganut kepercayaan asli, yakni suatu paham dokmatis yang terjalin dengan adat istiadat hidup dari berbagai macam suku bangsa. Pokok kepercayaannya adalah adat hidup yang mereka peroleh dari warisan nenek moyangnya. Kepercayaan asli tersebut -menurut Mukhlis dkk- umumnya bersifat animisme dan dinamisme. ${ }^{19}$

Salah satu wujud kepercayaan orang Bugis masa lalu yang menggambarkan ciri-ciri yang mengarah ke paham animisme atau dinamisme, yakni gaukeng. Gaukeng diyakini sebagai sosok makhluk halus penjaga sebuah komunitas. Dapat berupa segala sesuatu yang bentuknya tidak biasa atau mempunyai ciri-ciri aneh; bisa berupa biji buah yang telah kering, tunggul pohon, bajak tua, namun lebih banyak berupa batu. Leonard Y. Andaya mengatakan bahwa hampir tidak ditemukan pembahasan tentang asal-usul dan arti penting gaukeng bagi masyarakat Bugis di masa lalu. Namun demikian, terdapat indikasi kuat bahwa konsep serupa dengan gaukeng pada masyarakat Bugis tersebut dapat ditemukan di beberapa tempat lain di Asia Tenggara, bahkan umumnya di Asia. Paul Mus, seperti dikutip Andaya mengatakan bahwa kepercayaan terhadap dewa-dewa penjaga yang bersemayam di batu dapat ditemukan di Asia Tenggara, India, dan Cina, dan salah satu kepercayaan tersebut dapat ditemukan di Champa, daerah Vietnam bagian tengah sekarang. Orang Cham (sebutan bagi penduduk Champa) percaya bahwa Dewa Tanah, yang mengandung energienergi pemberi hidup bagi dunia, bersemayam dalam batu-batu tadi. Batubatu ini bukanlah representasi, namun Dewa Tanah sebenarnya dibuat kasat mata. Karena Dewa Tanah tidak mampu berkomunikasi seperti itu, jadi perlu ada perantara antara manusia dan dewa. Orang yang menjadi perantara diangkat oleh sesama mereka menjadi pemimpin spiritual dan keduniawian komunitasnya karena perannya sebagai juru bicara bagi Dewa Tanah. Batu-

${ }^{19}$ Lihat Mukhlis dkk., Sejarah Kebudayaan Sulawesi (Jakarta: Proyek Inpentarisasi dan Dokumentasi Sejarah Nasional, 1995), h. 31. 
batu keramat di Champa ini kelihatannya mempunyai kesamaan asal-usul, fungsi dan makna dengan gaukeng di Sulawesi Selatan. ${ }^{20}$

Seiring perjalanan waktu, terdapat indikasi kuat bahwa sebelum Islam menyebar ke wilayah Sulawesi Selatan, telah terjadi pengaruh agama Hindu dan Budha di wilayah ini. Namun demikian, pengaruh tersebut tidak terlalu kuat, seperti di wilayah Jawa dan Sumatera. Di Sulawesi Selatan tidak ditemukan keterangan bahwa pernah berdiri kerajaan Hindu dan Budha dan peninggalan-peninggalan budaya yang mencolok, seperti candi. Tidak diketahui pula waktu penyebaran Hinduisme dan Budhisme tersebut, namun jejak kepercayaan tersebut dapat ditelusuri dalam Sure I La Galigo sebagai salah satu karya tulis orang Bugis pra-Islam. Gambaran yang tampak dalam masyarakat yang dijadikan setting cerita tersebut memiliki kepercayaan terhadap sesuatu yang dianggap maha kuasa, pencipta alam, menentukan nasib manusia, menyuburkan tanah, dan lain-lain, yakni sesuatu yang disebut sebagai Dewata atau Dewatae; sebuah istilah yang jelas merujuk pada peristilahan kedua agama di atas.

Dengan mengacu pada I La Galigo, Christian Perlas membuat deskripsi singkat sistem kepercayaan orang Bugis pra Islam. Ia mengemukakan bahwa di atas segala-galanya terdapat satu entitas spiritual abadi yang dinamakan Dewata Sisine atau Dewa yang Maha Esa. Dari entitas ini -setelah tujuh lapis langit, bumi dan dunia bawah diciptakan- muncullah sepasang dewa yang disamakan dengan matahari dan bulan yang masingmasing bernama La Tepulangi (langit segenap) dan We Sengngeng Linge (ciptaan sempurna). Bersamaan dengan itu bintang-bintang pun tercipta. Dari pertemuan pasangan Sang Matahari dan Sri Bulan saat gerhana terjadi, lahirlah pasangan Dewa lain yang diberi tiupan nafas oleh Dewata Sisine. Pihak laki-laki dari pasangan tersebut juga seorang Dewa Matahari, bernama La Patinaga, sedangkan dewinya bernama We Lette Sompa (petir yang disembah). Dari pasangan terakhir ini, lahir 18 dewa atau (menurut naskah $I$

\footnotetext{
${ }^{20}$ Lihat Leonard Y. Andaya, The Heritage of Arung Palakka; A History of South Sulawesi (Celebes) In the Sevententh Century (Warisan Arung Palakka: Sejarah Sulawesi Selatan Abad ke17), trj. Nurhady Sirimorok (Cet. II, Edisi Indonesia, Makassar: Ininnawa, 2006), h. 16.
} 
La Galigo lainnya 14 dewa), yaitu sembilan (atau tujuh) pasangan kembar. Keturunan para dewa ini menikah satu sama lain, namun pasangan kembar tidak boleh menikahi kembarnya karena akan dinilai melakukan dosa. ${ }^{21}$

Keturunan delapan belas dewa inilah yang diceritakan secara panjang lebar dalam naskah I La Galigo. Di antara delapan belas dewa-dewi tersebut, Datu Patotoe (Sang Raja Penentu Nasib) dan istrinya Mutia Unru (Mutiara Badai) yang bergelar Datu Palinge (Sang Ratu Ibu) dianggap sebagai dewa tertinggi yang bertugas sebagai penjaga atau pemerintah seluruh jagat raya. Tempat bersemayamnya adalah di Botting Langi (langit tertinggi). Anak bungsu dari Datu Patotoe dan Datu Palinge, yakni La Tonge' Langi' yang bergelar Batara Guru, inilah yang diutus ke dunia tengah (dunia manusia). Setelah La Tonge' Langi' atau Batara Guru tiba bumi, ia kawin dengan We Nyili' Timo'. Keturunan Batara Guru dan We Nyili' Timo' inilah yang kemudian menurunkan para penguasa di Luwu yang menjadi tokoh utama cerita I La Galigo, yakni Sawerigading dan anaknya I La Galigo. ${ }^{22}$

Sejalan dengan deskripsi Perlas di atas, Andi Rasdiyanah mengatakan bahwa istilah Datuk Patoto'e atau To Palanroe bukanlah Tuhan, tetapi wakil Dewata Sisine atau Dewata Seuae (Tuhan yang Satu) dan menjadi raja di kerajaan "Langit”. Langit di sini tidak dapat diartikan secara harfiah, tetapi simbolis. Hal ini sesuai dengan paham kosmologi orang Sulawesi Selatan, bahwa dunia terbagi atas tiga kerajaan, yakni langi' (langit), ale kawa (bumi), dan uri' liu' (dunia bawah). ${ }^{23}$

Untuk berhubungan dengan Tuhan, manusia menggunakan medium roh nenek moyangnya yang datang merasuki manusia (dongkokeng). Manusia menyampaikan permohonannya kepada Tuhan melalui roh nenek moyang, karena Tuhan tidak makan, maka sesajen hanya diberikan roh nenek moyang. Raja di bumi dianggap mewakili arajang sebagai pemilik

\footnotetext{
${ }^{21}$ Lihat Christian Perlas, The Bugis (Manusia Bugis), trj. Abdul Rahman Abu dkk (Jakarta: Nalar bekerja sama dengan Forum Jakarta-Faris, EFEO, 2005), h. 9.

${ }^{22}$ Naskah I La Galigo yang digunakan dalam tulisan ini adalah naskah terjemahan oleh R.A. Kern, I La Galigo (Cet. II; Yogyakarta: Gadjah Mada University Press, 1993), h. 272.

${ }^{23}$ Gambaran kosmologi di atas disadur dari Andi Rasdiyanah, Integrasi Sistem Pangngadereng (Adat) dengan Sistem Syari'at sebagai Pandangan Hidup Orang Bugis dalam Lontara Latoa, Disertasi Doktor, IAIN Sunan Kalijaga Yogyakarta, 1995. h. 228.
} 
kerajaan. Arajang adalah wakil Dewata Seuwae (Tuhan) di bumi. ${ }^{24}$ Dengan konsep seperti ini, menurut A. Zainal Farid Abidin, seperti dikutip Andi Rasdiyanah bahwa agama pra Islam di Sulawesi Selatan dapat disebut sebagai monolatry, dan dalam pandangan Tobing sebagai Uhr-Monoteisme (monoteisme kuno). ${ }^{25}$

Sejalan dengan pandangan di atas, Mattulada mengatakan bahwa sebelum kedatangan Islam, sebagian masyarakat Sulawesi Selatan sudah mempunyai kepercayaan asli. Religi orang Bugis Makassar pada masa pra Islam, seperti tergambar dalam epik I La Galigo, sebenarnya sudah mengandung kepercayaan kepada Tuhan yang tunggal, yang disebut dengan beberapa nama, seperti Patotoe' (Dia yang menentukan nasib), Dewata Seuwae (Dewa yang tunggal, dan Turi' Ara'na (kehendak yang tinggi). ${ }^{26}$

Berikut gambarannya:

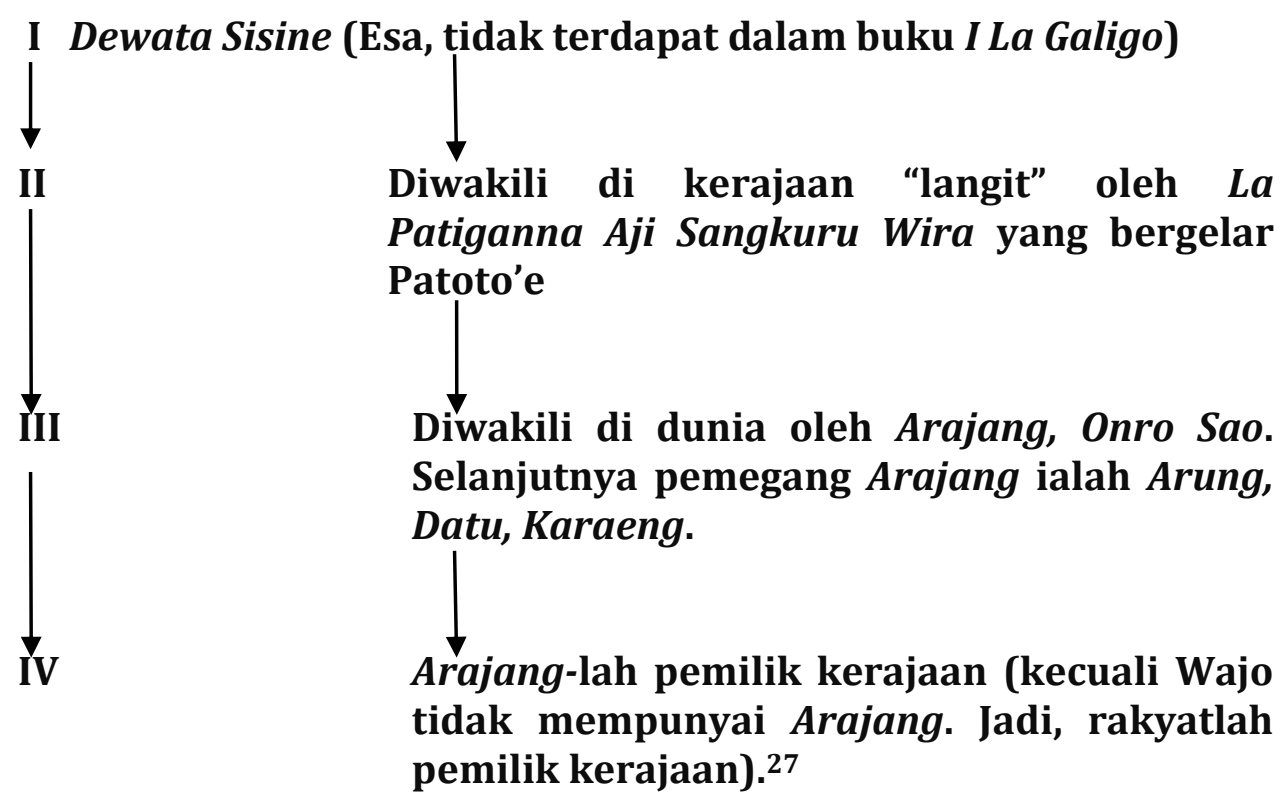

\footnotetext{
${ }^{24}$ Sampai hari ini masih terdapat pemahaman yang menyebutkan bahwa pemerintah (bupati, camat, dan bahkan kepala desa) dianggap sebagai Puang Alla Ta'ala Mallino. Wawancara dengan Andi Mallengkana Petta Lolo. Bone, 05 April 2013.

${ }^{25}$ Lihat Andi Rasdiyanah, Integrasi Sistem Pangngadereng (Adat) dengan Sistem Syari'at sebagai Pandangan Hidup Orang Bugis dalam Lontara Latoa, h. 229.

${ }^{26}$ Lihat Mattulada dalam M. Farid W. Makkulau, Manusia Bissu (Cet. I; Makassar: Refleksi, 2008), h. 19.

${ }^{27}$ Andi Rasdiyanah, Integrasi Sistem Pangngadereng (Adat) dengan Sistem Syari'at sebagai Pandangan Hidup Orang Bugis dalam Lontara Latoa, h. 230.
} 
Selain mengacu pada cerita I La Galigo, kepercayaan masyarakat Bugis pra Islam juga dapat ditelusuri melalui keberadaan komunitas Bissu di istana kerajaan Bugis, termasuk di Kerajaan Bone. Alasannya, karena umumnya ahli meyakini bahwa Bissu adalah semacam pendeta agama pada masa itu. Gilbert Albert Hamonik misalnya menyatakan bahwa di zaman kuno, kepercayaan di Sulawesi Selatan sangat kaya, jauh lebih kaya dari pada kepercayaan yang disebut dengan salah sebagai "animisme" saja. ${ }^{28}$

\section{Adanya Pengaruh Hindu Budha}

Kepercayaan masyarakat Sulawesi Selatan merupakan hasil evolusi dari kepercayaan zaman prasejarah. Pada zaman ini kepercayaan masyarakat Sulawesi Selatan tidak jauh berbeda dengan kepercayaan masyarakat lainnya di Nusantara. Kemudian, kepercayaan tersebut mendapat pengaruh dari agama yang pada saat itu sedang berkembang di Nusantara, yakni Hindu dan Budha. ${ }^{29}$

Sejalan dengan pandangan Hamonik di atas, C. Perlas menjelaskan bahwa salah satu indikasi tentang kemungkinan adanya pengaruh Hindu maupun Budha di Sulawesi Selatan (termasuk Bone) adalah adanya Bissu. Bissu adalah pendeta Bugis pra-Islam. Meskipun cara hidup mereka jauh berbeda dengan biarawan Budha, namun sebutan mereka dianggap berasal dari kata Sanskerta, yaitu bhiksu yang merujuk kepada pada biarawan Budha. Beberapa petunjuk lain, bahkan mengarah kepada adanya pengaruh aliran Budha Tantra yang dianut di Jawa dan Sumatera pada zaman kuno. Penganut Tantrisme di Tibet mempraktekkan cara mengeluarkan suara monoton bernada tinggi serta menggesekkan ujung jari pada tepi mangkuk untuk mencapai keadaan "trance". Gesekan ujung jari di tepi mangkuk yang dalam bahasa Bugis disebut gamaru adalah serapan dari bahasa Sanskerta, damaru.

\footnotetext{
${ }^{28}$ Lihat Gilbert Albert Hamonik "Kepercayaan dan Upacara dari Bugis Kuno: Pujaan Pendeta Bissu dalam Mitos I La Galigo" dalam Nurhayati dkk. ed., La Galigo: Menelusuri Jejak Warisan Sastra Dunia (Cet. I; Makassar: Pusat Studi La Galigo, Devisi Ilmu Sosial dan Humaniora, Pusat Kegiatan Penelitian Universitas Hasanuddin, 2003), h. 497.

${ }^{29}$ Lihat Gilbert Albert Hamonik "Kepercayaan dan Upacara dari Bugis Kuno: Pujaan Pendeta Bissu dalam Mitos I La Galigo" dalam Nurhayati dkk. ed., La Galigo Menelusuri Jejak Warisan Sastra Dunia, h. 497.
} 
Kemudian kaum Bissu tingkat tinggi bergelar dapunta, seperti halnya pendeta Budha Jawa dan Sumatera. Kata dapunta juga ditemukan pada salah satu prasasti peninggalan Kerajaan Sriwijaya di Kedukan Bukit Palembang. ${ }^{30}$

Hipotesis di atas semakin kuat jika dihubungkan dengan beberapa penemuan patung Budha Saraswati di beberapa titik di Sulawesi Selatan dan Barat, misalnya di daerah Bantaeng dan Mandar. Selain dua penemuan tersebut, terdapat indikasi lain, yakni dalam cerita I La Galigo sering muncul kata Kelling. Menurut C. Perlas, dalam bahasa Melayu kata Keling (dalam bahasa Bugis disebut Kelling) tidak hanya mengacu pada orang Tamil dari pantai Coromandel, tetapi juga mengacu pada semua pedagang dari India. Hal tersebut tidak harus diartikan bahwa banyak pedagang bangsa Keling yang berkunjung ke Sulawesi Selatan pada masa itu, meskipun itu bukan satu hal yang mustahil terjadi. Teks I La Galigo sendiri menyebut suatu pulau di Maluku yang disebut "Kelling" yang mengisyaratkan adanya pemukiman orang Tamil di sana. Selain itu, barang-barang yang dibawa ke Sulawesi oleh pedagang "Marangkabo" juga dinamai barang "kelling". Misalnya pakaian patola atau berbagai jenis bejana (balubu kelling), dan baja (bessi kelling). ${ }^{31}$

Namun demikian, apakah dapat dikatakan bahwa kepercayaan atau agama orang Bugis pra-Islam sepenuhnya agama Hindu atau Budha? Hal ini juga meragukan, sebab sampai saat ini di wilayah Sulawesi Selatan belum ditemukan artepak atau bentuk-bentuk peninggalan lainnya yang dapat dijadikan acuan untuk mengatakan bahwa pada masa lalu masyarakat di Sulawesi Selatan telah menganut kedua agama tersebut. ${ }^{32}$ Dalam hal ini, C. Perlas menyimpulkan bahwa dasar sistem religi orang Bugis sebenarnya bersifat pribumi, meski mungkin ditemukan adanya persamaan dengan konsep religi India, baik Hindu maupun Budha. Sekaitan dengan Bissu yang diakui sebagai bukti kuat adanya pengaruh Hindu-Budha, namun C. Perlas -

\footnotetext{
${ }^{30}$ Lihat Christian Perlas, The Bugis (Manusia Bugis), h. 86.

${ }^{31}$ Lihat Christian Perlas, The Bugis (Manusia Bugis), h. 87.

${ }^{32}$ Bandingkan misalnya dengan di Sumatera dan Jawa. Di kedua wilayah tersebut jelas terdapat banyak situs atau artefak yang menunjukkan bahwa pernah tumbuh dan berkembang komunitas, bahkan kerajaan yang menganut kedua agama tersebut. Sebagai contoh keberadaan Candi Borobudur, Prambanan, Mendut, dan lain-lain.
} 
mengutip pendapat Hamonik- menyatakan bahwa pendeta Bissu menggabungkan tiga rangkaian unsur, yakni:

1. Rangkaian pertama terkait dengan berbagai macam pemujaan, seperti pemujaan terhadap matahari dan bulan, serta penekanan khusus terhadap sebatang pohon yang dikeramatkan, tampaknya berhubungan dengan lapisan primordial. Semua aktivitas tersebut, para Bissu tidak jauh berbeda dengan sanro, dukun untuk kalangan umum. Rangkaian pertama ini dapat dikatakan asli bersumber dari tradisi Austrionesia.

2. Rangkaian kedua mencakup ambivalensi seksual para Bissu, yakni suatu hal yang menjadi ciri umum para penghubung dengan dunia roh di seluruh Austronesia. Hal semacam itu dapat ditemukan juga di kalangan orang-orang asli Taiwan, Kalimantan, dan sebelumnya juga di Jawa dan Bali, serta masyarakat Siberia dan Shaman (dukun) orang Indian Amerika. Dengan demikian, rangkaian unsur kedua bukan warisan murni Austronesia.

3. Sedangkan rangkaian ketiga, khususnya yang berkaitan dengan peran mereka sebagai pemimpin bagi elit penguasa sehingga para Bissu berkaitan pula dengan pengaruh India, entah Hindu atau Budha, tampaknya merupakan warisan utama dari periode $L a$ Galigo, yang bercirikan adanya hubungan antara golongan penguasa baru dengan dewata tertentu. ${ }^{33}$

\section{Simpulan}

Berdasarkan uraian di atas dapat dijelaskan bahwa kepercayaan masyarakat Bugis Makassar, mengalami evolusi yang cukup panjang. Pada tahap awal mereka jelas menganut kepercayaan animisme dan dinamisme, bahkan mungkin politeisme. Sebagaimana yang dikemukakan oleh Edwar Burnet Taylor (1832-1917) dalam karyanya yang terkenal, The Primitif Culture (1872) bahwa asal mula religi (agama) adalah bersamaan dengan

\footnotetext{
${ }^{33}$ Lihat Christian Perlas, The Bugis (Manusia Bugis), h. 109-110.
} 
munculnya kesadaran pada manusia akan adanya roh atau jiwa yang dipercaya mampu mempengaruhi kehidupan manusia, dan karena itu mereka layak untuk disembah dan diberi penghormatan sebagai tuhan. ${ }^{34}$ Kepercayaan ini, jelas dapat dialamatkan kepada penduduk awal Sulawesi Selatan, yakni gabungan antara ras Austro Melanesoid, Abris Sous Roche, dan Paleo Mongoloid yang mendiami pulau ini sekitar sejak 40.000 sampai dengan 30.000 tahun lalu. ${ }^{35}$ Kemudian disusul oleh bangsa Austronesia yang datang sekitar 3000 tahun SM. ${ }^{36}$

Pada tahap selanjutnya, masyarakat Bugis Makassar menerima pengaruh dari tradisi Hindu-Budha. Hal ini terlihat dalam seluruh rangkaian cerita I La Galigo yang menyebut para penguasa langit (botting langi) dengan istilah-istilah yang mengacu kepada tradisi ketuhanan Hindu-Budha. Meskipun demikian, tidak ditemukan indikasi kuat bahwa agama HinduBudha tersebut pernah dianut sepenuhnya oleh masyarakat Bugis. Pada tahap ini kelihatannya kepercayaan tersebut lebih mengarah kepada sebuah kepercayaan singkretis antara warisan Austronesia yang bertumpu pada kepercayaan tentang adanya roh-roh dan unsur-unsur Hindu-Budha yang datang kemudian.

Dalam proses pergumulan kedua unsur keyakinan tersebut tidak dapat dipastikan unsur mana yang lebih dominan. Sebab, istilah-istilah yang tampak di permukaan benar lebih cenderung bercorak Hindu-Budha, namun pada lapisan dalamnya masih didominasi oleh nuansa yang bercorak kepercayaan yang bersifat animisme atau dinamisme. Kesimpulan ini agaknya semakin kuat jika dikaitkan dengan fakta tidak ditemukannya peninggalan-peninggalan budaya meteril/fisik Hindu-Budha di wilayah ini, seperti candi, sebagaimana di Sumatera dan Jawa.

\footnotetext{
${ }^{34}$ Lihat Dadang Mahmud, Sosiologi Agama (Bandung: Remaja Rosda Karya, 2000), h. 24-28.

${ }^{35}$ Lihat Christian Perlas, The Bugis (Manusia Bugis), h. 24.

${ }^{36}$ Tentang penduduk awal Pulau Sulawesi Selatan yang dialamatkan kepada bangsa Austronesia dapat dibaca dalam Robert Dick-Read, The Phantom Voyagers; Evidence of Indonesian Settlement in Africa in Ancient Times (Penjelajah Bahari: Pengaruh Peradaban Nusantara di Afrika), trj. Edrijani Azwaldi, (Cet. I; Bandung: Mizan Pustaka, 2008), h. 19-20.
} 
Dalam proses dialektika dan pergumulan singkretisme tersebut, terdapat satu hal yang menarik bahwa pada tahap ini masyarakat Bugis Makassar mulai memiliki kesadaran akan adanya Tuhan yang Maha Esa, yang dalam bahasa lokal disebut sebagai Dewata Sisinie atau Dewata Seuwae. Keyakinan ini -seperti yang dapat dilihat kemudian- menjadi salah satu di antara beberapa faktor penting sehingga masyarakat Sulawesi Selatan dengan mudah menerima dan beradaptasi dengan sistem kepercayaan agama Islam. Kalaupun pada awalnya beberapa kerajaan Bugis yang menolak menerima Islam, hal itu bukan semata-mata faktor keengganan berganti keyakinan, tetapi terdapat indikasi bahawa hal itu lebih cenderung kepada gengsi politik kekuasaan.

\section{Daftar Pustaka}

Albert Hamonik, Gilbert. "Kepercayaan dan Upacara dari Bugis Kuno: Pujaan Pendeta Bissu dalam Mitos I La Galigo" dalam Nurhayati dkk. ed., La Galigo: Menelusuri Jejak Warisan Sastra Dunia. Cet. I; Makassar: Pusat Studi La Galigo, Devisi Ilmu Sosial dan Humaniora, Pusat Kegiatan Penelitian Universitas Hasanuddin, 2003.

Dick-Read, Robert. The Phantom Voyagers; Evidence of Indonesian Settlement in Africa in Ancient Times (Penjelajah Bahari: Pengaruh Peradaban Nusantara di Afrika), trj. Edrijani Azwaldi. Cet. I; Bandung: Mizan Pustaka, 2008.

Kern, R.A. I La Galigo. Cet. II; Yogyakarta: Gadjah Mada University Press, 1993.

Makkulau, M. Farid W. Manusia Bissu. Cet. II; Makassar: Refleksi, 2008.

Mukhlis dkk. Sejarah Kebudayaan Sulawesi. Jakarta: Proyek Inpentarisasi dan Dokumentasi Sejarah Nasional, 1995.

Mattulada dalam M. Farid W. Makkulau, Manusia Bissu. Cet. I; Makassar: Refleksi, 2008.

Mahmud, Dadang. Sosiologi Agama. Bandung: Remaja Rosda Karya, 2000.

Perlas, Christian. The Bugis (Manusia Bugis). Trj. Abdul Rahman Abu dkk. Jakarta: Nalar bekerja sama dengan Forum Jakarta-Faris, EFEO, 2005. 
Reid, Anthony. Southeast Asia in the Age of Commerce 1450-1680 (Asia Tenggara dalam Kurun Niaga 1440-1680). Trj., R. Z. Leirissa dan P. Soemitro. Jilid 2. Cet. II; Jakarta: Yayasan Obor Indonesia, 2011.

Rasdiyanah, Andi. Integrasi Sistem Pangngadereng (Adat) dengan Sistem Syari'at sebagai Pandangan Hidup Orang Bugis dalam Lontara Latoa, Disertasi Doktor, IAIN Sunan Kalijaga Yogyakarta, 1995.

Y. Andaya, Leonard. The Heritage of Arung Palakka; A History of South Sulawesi (Celebes) In the Sevententh Century (Warisan Arung Palakka: Sejarah Sulawesi Selatan Abad ke-17), trj. Nurhady Sirimorok. Cet. II, Edisi Indonesia, Makassar: Ininnawa, 2006. 